\title{
$\mathbf{R}$

\section{UMA REFLEXÃO SOBRE CIDADE, CONFLITO E A “OCUPAÇÃO” COMO LÉXICO DA AGÊNCIA POLÍTICA DO RECIFE CONTEMPORÂNEO A PARTIR DO MOVIMENTO OCUPE ESTELITA ${ }^{1}$}

\author{
Izabella Medeiros ${ }^{2}$ \\ Francisco Sá Barreto 3
}

Resumo: Este trabalho é produto de uma pesquisa em desenvolvimento cujo objetivo central é investigar a interdependência entre os discursos da tradição/identidade e do progresso/desenvolvimento na produção de uma cultura política da cidade observados em três tempos específicos $(1937,1971$ e 2014) na cidade do Recife-PE. O presente trabalho decorre do terceiro recorte temporal e tem como objetivo entender de que maneira a ocupação do Movimento Ocupe Estelita sintetiza as relações de conflito observadas na cultura política da cidade do Recife deste início de século. Para isso, realizamos pesquisa documental em jornais e na internet e também produzimos nossos próprios diários de pesquisa.

Palavras-chave: Cidade. Movimento Ocupe Estelita. Cultura Política. Segregação urbana. Novas agências políticas.

\section{UNA REFLEXIÓN SOBRE LA CIUDAD, EL CONFLICTO Y LA “OCUPACIÓN" COMO LÉXICO DE LA AGENCIA POLIITICA CONTEMPORÁNEA DE RECIFE A PARTIR DEL MOVIMIENTO OCUPE ESTELITA}

Resúmen: Este trabajo es producto de investigación en desarrollo cuyo objetivo central es investigar la interdependencia entre los discursos de tradición/identidad y progreso/desarrollo en la producción de una cultura política de la ciudad observados en tres momentos específicos $(1937,1971$ y 2014) en la ciudad de Recife-PE. El presente trabajo parte del tercer marco de tiempo y tiene como objetivo comprender cómo la ocupación del Movimiento Ocupe Estelita sintetiza las relaciones de conflicto observadas en la cultura política de la ciudad de Recife a principios de este siglo. Para esto, llevamos a cabo investigaciones documentales en periódicos y en internet, y también producimos nuestros propios diarios de investigación.

Palavras-clave: Ciudad. Movimiento Ocupa Estelita. Cultura política. Segregación urbana. Nuevas agencias políticas.

\footnotetext{
${ }^{1}$ Artigo produzido como produto de pesquisa fomentada pela FACEPE (Fundação para o Amparo da Ciência em Pernambuco). Esta é uma versão modificada de uma versão anteriormente publicada nos Anais do 410 Encontro Anual da ANPOCS, 2017, cujo título é: A "ocupação" como léxico da agência política nas cidades contemporâneas: o caso do Movimento Ocupe Estelita, em Recife - Pernambuco.

${ }^{2}$ Doutora em Sociologia, pesquisadora do Grupo de Pesquisa Curupiras: Colonialidades e Outras Epistemologias, e-mail: bellamedeiros@gmail.com.

3 Doutor em Sociologia, professor do Departamento de Antropologia e Museologia da UFPE, pesquisador do Grupo de Pesquisa Curupiras: Colonialidades e Outras Epistemologias, e-mail: xicosabarreto@gmail.com.
} 


\title{
A REFLECTION ABOUT THE CITY, CONFLICT AND THE "OCCUPATION" AS A LEXICON OF THE CONTEMPORARY RECIFE POLITICAL AGENCY FROM THE OCUPE ESTELITA MOVEMENT
}

\begin{abstract}
This paper is a result of research in progress, which the main objective is to investigate the relationship between the discuss of tradition/identity and progress/developing in a political culture in three specific moments $(1937,1971$ and 2014) in Recife, Pernambuco. In this paper, we offer a debate on the occupy movements and the Ocupe Estelita as a synthesis of several urban conflicts at the beginning of the 21st century in Recife. For it, we made a documental research in newspapers and internet as well as our own research diaries.
\end{abstract}

Keywords: City. Ocupe Estelita Movement. Urban segregation. New political agency.

\section{POR QUE DESTRUÍRAM O ACAMPAMENTO DO ESTELITA? CIDADE, CONFLITO E POLÍTICA URBANA}

No dia 17 de junho de 2014, a cidade do Recife estava menos movimentada que o de costume. Naquele dia, a seleção brasileira de futebol jogou sua segunda partida na Copa do Mundo sediada pelo Brasil, empatando com o México em zero a zero. Em dias de jogos do Brasil, não é raro - ou não era -, além do trânsito caótico nas horas que antecedem às partidas, um quase fantasmagórico esvaziamento das ruas devido ao forte apelo causado pelos jogos. Além disso, o megaevento em questão instituiu uma série de estratégicas intervenções sobre a gestão de vida e consumo coletivos nas grandes cidades brasileiras, o que modificou seu funcionamento regular durante os trinta dias de Copa.

Segundo o artigo 56 da Lei 12.663/2012, a chamada "Lei da Copa", os dias de jogos seriam declarados feriados nacionais, bem como seria possível a cada uma das sedes de partidas das demais seleções fazer o mesmo com feriados locais. Durante todo o evento, mas especialmente nas datas em questão, a atuação da força policial receberia o reforço dos poderes militares e prisões de manifestantes e repressões a "situações de risco ao evento" poderiam ser, sem a devida apreciação dos órgãos de justiça, efetuadas. O dia 17 de junho, em Recife, foi, portanto, um dia de ruas vazias, inapropriado para manifestações a respeito de temas que não fossem referentes ao jogo e/ou à Copa, e, então, um dia estratégico para a atuação da força policial.

Esse foi o dia escolhido pelo Governo do Estado para cumprir um mandato de reintegração de posse dos antigos galpões da Rede Ferroviária Federal (RFFSA, conhecida pelo grande público como Refesa) no Cais José Estelita, destruindo o 
acampamento que estivera montado ali nos cinquenta e um dias anteriores. Uma manhã de cidade vazia foi o recurso cruel para desmontar com violenta atuação do Batalhão de Choque o projeto de zona urbana viva em que se transformava o acampamento do Ocupe Estelita. Os participantes do movimento - de difícil tipificação devido à característica difusa dos grupos envolvidos - montaram uma barreira humana nos portões dos galpões e logo se converteram em alvo fácil do uso da força policial, das balas de borracha e bombas de gás lacrimogênio utilizadas pela polícia para garantir a passagem dos veículos empregados na destruição das estruturas montadas pelo acampamento do movimento. Toda a ação durou pouco mais de uma hora, rendendo um sem número de feridos e, como se pretendia, a restituição da posse sobre os galpões.

O evento em questão é paradigmático para as reflexões deste trabalho. Em primeiro lugar, ele narra uma passagem recorrente na história da moderna urbanização da cidade do Recife, sempre marcada por desapropriações e deslocamentos populacionais, como podemos, com facilidade e de forma emblemática, verificar nas décadas de 1910, 1940 e 1970. Em segundo lugar, é paradigmático devido à natureza do movimento - que se articulara durante o acampamento - e a sua relação com a cidade e seus dispositivos de gestão, o que sugeriria a reintegração de posse do terreno da RFFSA apenas como uma emulação da razão fundamental da destruição do acampamento: silenciar o movimento em questão. Mas isso ainda não é tudo. Em terceiro lugar, o é porque traduz uma condução específica das políticas de gestão da cidade, a partir das quais o poder público efetivamente serve à manutenção de leis e a um jogo político que garantem a gerência das intervenções urbanas sobre os espaços da cidade à iniciativa privada. Ou seja, nesse modelo de cidade, o Estado existe para criar e garantir boas oportunidades à iniciativa privada - empresas como: construtoras, escritórios de arquitetura, incorporadoras e imobiliárias -, comprometida com a requalificação e a viabilidade econômica de antigas zonas de degradação da cidade.

Nesta discussão, vale destacar que a história da urbanização da cidade do Recife, ao longo do século $\mathrm{XX}$, é fundamentalmente marcada pelas remoções e políticas de requalificação. Durante os anos 1910, praticamente todo o Bairro do Recife foi reconstruído. Uma narrativa desenvolvimentista seria curiosamente 
vinculada a uma identidade tradicionalista para remover o casario de arquitetura colonial. O projeto previa sua substituição por novos edifícios e avenidas amplas para automóveis, além de otimizar o funcionamento do porto. O modelo da Paris Haussmanniana marcaria o discurso de modernização da já antiga cidade colonial num esforço de substituição do velho pelo novo. O mesmo espírito pode ser verificado ao final dos anos 1930 e durante toda a década de 1940, quando dos governos interventores do Estado Novo sobre o município e da expansão das políticas de "revitalização" e remoção populacional para além do Bairro do Recife (SÁ BARRETO; MEDEIROS, 2017, 2020b).

Tais políticas estiveram concentradas fundamentalmente em zonas de centro ampliadas, dirigidas aos bairros de Santo Antônio e São José. A abertura de grandes avenidas, saneamento da região e construção de novos prédios se somariam, neste caso específico, à Liga Social Contra o Mocambo, os quais promoviam a remoção daquela que representava, ao final dos anos 1930, 66\% das edificações da cidade: a moradia produto da arquitetura espontânea (PONTUAL, 2001).

Já nos anos 1970, a sequência dessas intervenções ganha contornos de políticas culturais e a razão desenvolvimentista efetivamente se liga a conservação da cultura local na produção do que podemos chamar de uma cultura do passado-presente para a construção da cidade contemporânea. É o que se pode observar na conclusão de projeto, ainda dos anos 1920, de abertura da Avenida Dantas Barreto e dos produtos a ela associados, tais como a conversão da antiga Casa de Detenção na atual Casa da Cultura (SÁ BARRETO; MEDEIROS, 2020b).

Desde o texto que justifica o tombamento do Bairro do Recife, em 1998, observamos (sem grandes dificuldades) uma progressiva gestão privada das grandes intervenções urbanas, que tomam específicos usos da cultura como recurso para a produção de razões públicas para remoções e enobrecimento de regiões inteiras da cidade (LEITE, 2007; YÚDICE, 2004; SÁ BARRETO \& MEDEIROS, 2017). O tombamento do citado bairro foi apenas a cereja do bolo que já era o intenso processo de gentrificação ao qual a região era submetida desde o início da década de 1990. Mas ele seria, também, um poderoso indicativo das políticas para a cidade no início do século XXI. 
Em primeiro lugar, um certo uso dos tombamentos agregaria um valor específico à região, o que possibilitaria um sofisticado empreendimento de gestão da circulação de pessoas, convertendo o bairro em objeto específico de interesse do mercado do turismo global, de um lado, e de um conjunto de empresas de tecnologia da informação, de outro lado. A exclusão ou o isolamento de populações pobres na região foi aprofundada por dispositivos policiais autorizados, por exemplo, a impedir a circulação de menores desacompanhados nas principais ruas do bairro. Em segundo lugar, a disposição para a gentrificação na região permitira a extensão das políticas de requalificação aos equipamentos culturais, o que significou a instalação de produtos voltados para o consumo cultural e a tomada do projeto ampliado de "revitalização" de toda a região como um complexo programa para a Cultura pernambucana. Um exemplo é a reforma dos antigos armazéns do antigo porto para instalação de lojas e restaurantes, como também a abertura de alguns museus no bairro.

Não por acaso, quando do leilão dos galpões da antiga RFFSA, em 2008, os jornais pernambucanos de grande circulação apresentaram os projetos para aquela região em suas seções de cultura, e não de cidades ou economia. Esse movimento já podia ser observado na gestão das políticas de cultura ainda no governo FHC/Weffort, quando as leis de renúncia fiscal ganharam corpo no Brasil e os investimentos em cultura puderam converter-se, efetivamente, em objeto da iniciativa privada.

Ao longo do século XX e neste início do XXI, não foram poucas as iniciativas que procuraram resistir a esses empreendimentos, eventualmente logrando algum sucesso com o retardo das intervenções ou modificações no projeto original - como conseguiu o próprio Movimento Ocupe Estelita. A história da urbanização da cidade do Recife nesses 110 anos, contudo, descreve uma progressiva sofisticação das técnicas de apartação, tão características da moderna grande cidade brasileira, movimento já tão bem observado por alguns pesquisadores que se dedicaram a esse exercício (SEVCENKO, 2010; CALDEIRA, 2000).

\section{OCUPAR, RESISTIR: O QUE A OCUPAÇÃO NOS DIZ DAS CIDADES DE INÍCIO DO XXI?}

A emergência dos movimentos Ocupe, seja para pensar a crítica ao mercado financeiro - como no caso do Occupy Wall Street -, ou se rebelar contra o aumento 
das passagens de ônibus - razão que funda o Movimento Passe Livre -, indica alguma mudança nas políticas de resistência? Representam, esses movimentos, extensões de uma outra gramática da mobilização que os diferem dos já existentes programas de ocupações urbanas, por exemplo? Nessa senda de questionamentos, o objetivo geral deste trabalho é discutir as experiências políticas da ocupação e agência na cidade contemporânea (Recife, no caso) a partir do Movimento Ocupe Estelita.

Na pesquisa da qual decorre o objeto e a reflexão em questão, cruzamos as políticas de intervenção do Estado em outros dois recortes temporais específicos, a saber, o final dos anos 1930 e o início dos anos 1970, quando drásticas modificações urbanístico-arquitetônicas em Recife foram realizadas pelas gestões municipais e estaduais. Nesses recortes, uma razão desenvolvimentista complexamente cruzada por uma narrativa heroica da tradição compõe o cenário do que estamos compreendendo como um urbanismo de suplício, ou sofisticadas políticas de exclusão de grupos populacionais específicos das zonas de centro, objeto de interesse estratégico da especulação na cidade. O Projeto Novo Recife (recorte de 2014), montado sobre o discurso do desenvolvimento e de preservação de características de uma cidade forte e pioneira - ou seja, aqui também há o elemento da tradição -, não oferece mais do que a sofisticação das políticas de interdição, em um movimento ainda mais ardiloso do que aquele a que assistimos durante o empreendimento de gentrificação dos anos 1990 (LEITE, 2007).

O elemento novo trazido pelo terceiro recorte da pesquisa, contudo, é exatamente o conjunto de políticas de resistência resumido pela ideia contemporânea de Ocupação. Se elementos fundamentais para a emergência do conceito já estavam discutidos em outro momento de debates sobre a cidade, sob outras matrizes semânticas, presentes em textos clássicos como os de Jane Jacobs (1961[2014]) discutindo o uso como sintoma de vida nas grandes cidades -, ou os de Henri-Pierre Jeudy (2005) - refletindo a respeito da mania preservacionista na estética urbana contemporânea -, é com o conjunto de levantes contra o mercado financeiro ou políticas de austeridade que novos movimentos se fazem familiares a partir do léxico da Ocupação urbana, os ditos movimentos Occupy.

A ocupação de zonas interditadas pelas lógicas do esvaziamento urbano representou o elemento simbólico desses esforços de associação e resistência que, em 
Recife, são bem representados pelo difuso Movimento Ocupe Estelita. Não por acaso, desde seu início, os levantes, as críticas e os produtos das resistências apontavam para o desenvolvimentismo como elemento fundamental do projeto de cidade contemporânea que atacavam; e defendiam um outro modelo de cidade por meio de uma narrativa da tradição - "cidade de lutas", "história de guerreiros", "memória de resistência", "tradição cultural”, "identidade revolucionária" - enquanto elemento central na composição de seus discursos ${ }^{4}$.

Dessa forma, grupos associados ao difuso movimento, formados a partir de matrizes diversas, ofereceram produtos também intensamente diversos como alternativas de uso para o espaço em debate. De equipamentos culturais (parques, museus, memoriais, cinemas) até o desejo de "conservar" o vazio como linguagem de uso da cidade, uma miríade de alternativas passou a representar a profusão de fios que poderiam produzir o tecido urbano de um cosmopolita Recife contemporâneo.

Diante disso, tentamos compreender, com a reflexão que por ora se desenvolve, como o Movimento Ocupe Estelita, por meio do binômio ocupaçãoagência, sintetiza (ou pode sintetizar) as relações de conflito observadas na cultura política da cidade do Recife deste início de século.

Não podemos negar que, no Brasil, os esforços políticos de ações coletivas como essa foram fortemente estimulados pelas grandes manifestações de rua do Junho de 2013. Os movimentos de rua se traduziram em séries de manifestações pelo país, quando espaços urbanos se tornaram palco para manifestações de dupla face que, de um lado, flertavam perigosamente com um discurso ufanista e em grande desuso, e, de outro lado, representavam um esforço para profanação de uma esfera pública excessivamente institucionalizada e partidarizada (BENZAQUEN \& SÁ BARRETO, 2013; HABERMAS; 2003). Esse cenário é o que tentaremos compreender melhor na seção a seguir.

\footnotetext{
${ }^{4}$ Como vimos, gestão pública e ativistas se utilizam da tradição enquanto elemento articulador de seus discursos, mas é preciso dizer que os sentidos em torno desse léxico (e de seus correlatos) negociados por cada um dos grupos - movimento versus gestão pública + empresas - se localizam em campos semânticos e políticos distintos. E, além disso, os interesses em jogo são radicalmente diferentes.
} 


\section{DO JANO BRASILEIRO ÀS OCUPAÇÕES COMO LINGUAGEM: O MOVIMENTO OCUPE ESTELITA}

Fundamentalmente desde 2011, um conjunto de mobilizações de grandes contingentes populacionais tem exigido esforço de diversas frentes para que se compreenda suas estratégias, agendas, seus sentidos e resultados produzidos. Dos veículos de comunicação de massa de uma grande mídia aos centros universitários, em sua pluralidade de áreas, as teses sobre uma multiplicidade de movimentos aproximados representam, ao mesmo tempo, de um lado, esforços para identificar rapidamente os mecanismos de esvaziamento das ruas relacionados aos programas do que tomamos genericamente por uma miríade de projeções de resistência a partir do elemento feito comum pelos movimentos Ocupe ${ }^{5}$; e, de outro lado, representam os inícios de programas de investigação que têm a identificação de uma nova linguagem das ruas como ponto de partida para uma renovada tarefa política fortemente vinculada (aparentemente) a um novo projeto de "coisa pública".

Nesse cenário, o Occupy Wall Street e a Primavera Árabe funcionaram como importantes células para o desenvolvimento e a visibilidade de um sem número de projetos de nova tomada das ruas e/ou de manifestações de contra-uso de zonas urbanas tradicionalmente ocupadas pelo dispositivo estatal e seus multifacetados mecanismos. Assim, os espaços urbanos de grandes cidades brasileiras funcionaram como palco para tradução desses esforços em uma série de ocupações que, desde 2011, pretendem funcionar enquanto lugar que expressa e sintetiza as reivindicações por novas linguagens para a vida na metrópole. Uma miríade de objetos tem funcionado como mote para esses levantes que tiveram sua máxima expressão, num primeiro momento de análise, no junho de 2013 (BENZAQUEN; SÁ BARRETO, 2013).

Naquela ocasião, contudo, os instrumentos de reivindicação estiveram descolados desses programas de nova ocupação dos espaços públicos. A partir de complexo cruzamento entre o sentimento nacionalista oitocentista e uma forte crítica ao projeto de Estado brasileiro, o "junho de 2013" representou, com muito expressiva reunião populacional, uma avalanche daquilo que se pretendeu traduzir no imperativo

\footnotetext{
${ }^{5}$ Seja na descrença dos movimentos Ocupe nas formas tradicionais de protesto, seja na descrença dos grupos tradicionais nas formas de luta traduzidas pelos movimentos Ocupe.
} 
de um novo programa de vida política. O junho brasileiro, nesse contexto, bem pode ser chamado de Jano, como referência ao deus da mitologia romana, cuja dupla face traduz o difícil trânsito entre os antigos hábitos e as novas compreensões (BENZAQUEN; SÁ BARRETO, 2013).

No dia 2 de fevereiro de 2012, por exemplo, a Folha de Pernambuco estampou em sua capa a palavra "Baderna", em letras garrafais, como léxico autoexplicativo para o conjunto de manifestações estudantis pela melhoria do transporte público. Dez dias depois, Diario de Pernambuco e Jornal do Commercio, os principais jornais do estado, seguiram a mesma linha editorial, publicando, respectivamente - e de forma mais sofisticada -, "A cidade não aguenta mais isso!" e "Você também foi afetado no trânsito pelos protestos dos estudantes? Compartilhe a sua história". Nos três casos, as empresas de mídia em questão, que se apresentam como a mais equilibrada tradução das vozes das cidades $^{6}$, reforçam a rejeição da cidade a manifestações daquele tipo, sugerindo que a população não suporta o comportamento profano que rasura a face envelhecida de Janus.

Pouco mais de um ano depois, no olho do furacão de protestos que pareciam varrer uma experiência envelhecida da agência política no Brasil, traduzida com grande entusiasmo por um sem número de veículos de grande mídia em todo o país, no dia 21 de junho de 2013, o Diario de Pernambuco estampou em sua capa: "A maior arquibancada do Brasil", junto a um conjunto de fotografias que retratavam as manifestações nas mesmas regiões da cidade reportadas pelas matérias de fevereiro de 2012. O jornal pegava carona nas campanhas publicitárias do evento teste da Copa do Mundo que aconteceria no ano seguinte, mas não somente. O fazia para reforçar a suposta insuportável relação entre a população e uma forma de funcionamento da macro política institucional, que esses veículos chamavam apenas de "política", e que não podia ser compatível, por exemplo, com a luta contra a corrupção. Consequentemente, a narrativa sobre as manifestações transitou entre os clichês dos supostos vandalismos estudantis cotidianos ao pretenso exercício pleno da experiência democrática, mecanismo que não comportava, inclusive, qualquer manifestação partidária. Os efeitos dessa forma discursiva ainda são, à exaustão, estudados.

\footnotetext{
${ }^{6}$ Referimo-nos aqui às principais cidades que compõem a região metropolitana de Recife - Recife, Olinda, Paulista, Camaragibe e Jaboatão dos Guararapes.
} 
Esse trânsito, pensamos nós, não revela somente a contradição ou a disposição dos veículos hegemônicos de comunicação de massa para se adequar às demandas de um leitor que não pode deixar de ser consumidor. Revela, também, parte da ambiguidade do Jano brasileiro, forjado na curiosa substituição parcial da intolerância da cidade burguesa aos levantes de rua à simpatia pelos movimentos, celebrada por uma forte política de adesão da classe média a algumas formas dos ditos novíssimos movimentos sociais. Assim, os movimentos poderiam ter, ao mesmo tempo, forte discurso cívico/nacionalizante sem que, para isso, assumissem claramente uma posição política que tivesse algum eco na estrutura do Estado e de seus dispositivos (GOHN, 2017).

Mais firme que essa passagem, contudo, é possivelmente um outro elemento da condição bifronte dos levantes de junho. Trata-se da forte conexão com uma simbologia do cívico, braço fortemente nacionalizante (ou nacionalista) de uma representação geral do dito Jano brasileiro. Todos os dias, a grande mídia veiculou a forte relação entre os movimentos de rua e o aprofundamento (ou renascimento) do sentimento de pertencimento nacional, na maioria das teses midiaticamente populares, condição fundamental para uma espécie de reconstrução política do nacional. É o que Žižek (2005) chamaria de reset político, ou o esforço para reiniciar a experiência política como se isso efetivamente fosse possível.

A razão de parte dos usos políticos dos movimentos de junho foi a possibilidade de fazer política negando a política. Não por acaso, os movimentos que se seguiram aos levantes foram, de um lado, aqueles que destacaram os riscos dessa característica - e procuraremos abordar o Ocupe Estelita a partir desse lugar de análise - e, de outro lado, os grupos que surfaram no discurso do contra-político como estratégia para sustentar, com forte tom cívico-nacionalista, posições conservadoras e totalizantes. Esse segundo grupo pouco nos interessa aqui neste trabalho.

Procuramos capturar os traços dos levantes que traduziram movimentos possíveis para a crítica a um lugar comum das identidades, sejam elas políticopartidárias, raciais, de gênero, entre outras, mobilizadas para produzir espaços políticos em desconstrução e reconstrução. Esses movimentos, a partir do que pudemos observar, descrevem funcionamentos que têm a cidade como lugar epistemológico fundamental e a rasura de lugares comuns de segregação urbana como 
principal objeto. É nesse aspecto que o Movimento Ocupe Estelita, doravante MOE, costura o debate que aqui ensaiamos.

Quando da aprovação do projeto Novo Recife, em 2012, por um CDU (Conselho de Desenvolvimento Urbano) montado de forma irregular, as maiores manifestações começaram a se materializar. Seja a partir da formação do grupo Direitos Urbanos ${ }^{7}-$ hoje com mais de 30 mil membros -, seja a partir da iniciativa de matrizes diversas sobre as intervenções que se projetavam para a região do Cais José Estelita, uma série de materiais começaram a ser apresentados com a finalidade de denunciar a série de irregularidades que envolvia o projeto. Falta de estudos de impacto urbano e ambiental, fraude no leilão dos galpões em 2008, inexistência de audiências públicas para discutir as possibilidades e interesses para a área, formação irregular do CDU, são, todos esses, apenas elementos formais que indicam um tipo de produção de cidade que está distante de constituir a exceção. A ausência de regra ou a inaplicabilidade da normativa é, pelo contrário, o traço mais comum das grandes intervenções na moderna urbanização da cidade de Recife. Elementos análogos ao do Projeto Novo Recife (doravante PNR) - eventualmente constando inclusive com o mesmo nome em questão - podem ser verificados em outros recortes temporais na história recente da cidade, como citamos acima. As brechas excessivas produzidas sobre a norma, sobre um plano diretor pouco eficiente diante das grandes construtoras e desse tipo de capital (rentista), findaram por mobilizar um conjunto difuso da população em torno de elementos específicos do projeto em questão.

O trabalho de Lúcia Veras (2014) é mais do que suficiente para compreender esses antecedentes quando, a partir de cuidadoso estudo sobre as políticas de produção da paisagem urbana naquela região da cidade, tomando como referência o caso específico das "Torres Gêmeas" do Recife, expõe a fragilidade do dispositivo de legalidade contra os grandes interesses da especulação imobiliária. A razão desenvolvimentista em sua nova fase, mobilizada especificamente pela especulação, precede e rasura as arenas públicas de vida e consumo coletivos na cidade de início do século XXI. A construção das duas torres em questão, concluída em 2008, descreve

\footnotetext{
7 Para quem tiver interesse no debate, publicamos o seguinte artigo: Limites e possibilidades de agências digitais para outras urbanidades possíveis - o caso do grupo de direitos urbanos em Recife, Pernambuco.
} 
irregularidades desde o leilão do terreno, avaliado em mais de 3 milhões de reais, mas arrematado em certame com concorrência única por 600 mil reais. As torres são um dispositivo paradigmático do projeto de cidade do século XXI.

Elas não indicam somente, como destaca Veras (2014), um desacordo explícito entre as duas construções e a skyline de toda a região. Fazem mais do que isso. Elas aprofundam uma cidade que tem seu desenvolvimento intensamente pautado em empreendimentos de apartação e que vê representado nos grandes edifícios o poder simbólico dos sobrados ou mesmo da antiga casa grande de engenho, discussão que desenvolveremos com mais cuidado adiante. Podemos dizer que naquele espaço urbano se traduz aquilo que Sharon Zukin (2000) chama de paisagens de poder.

A mobilização das reações às duas torres foram o ponto de partida das articulações para movimentações mais intensas contra o PNR. O que é, nesse contexto, o MOE?

Desde a década de 1990, variadas formas reivindicativas de ocupar as ruas ${ }^{8}$ se apresentaram enquanto uma forma original de protesto. Mais recentemente, finais de 2010 e em 2011, assistimos aos protestos no mundo árabe, que ficaram conhecidos como "Primavera Árabe". Aconteceram revoluções na Tunísia e no Egito, uma guerra civil na Líbia, grandes protestos na Argélia, Bahrein, Djibuti, Iraque, Jordânia, Síria, Omã e lémen e protestos menores no Kuwait, Líbano, Mauritânia, Marrocos, Arábia Saudita, Sudão e Saara Ocidental. Os protestos têm compartilhado técnicas de resistência civil, fazendo greves, manifestações, passeatas e comícios, e também fazendo o uso das mídias sociais, como Facebook, Twitter e Youtube, para organizar, comunicar e sensibilizar a população e a comunidade internacional (BENZAQUEN; SÁ BARRETO, 2013).

O uso das redes sociais na internet também foi o que divulgou o Movimento $12 \mathrm{M}$ em Portugal. $12 \mathrm{M}$ porque o manifesto publicado no Facebook incitava à

\footnotetext{
${ }^{8}$ Em janeiro de 1994, milhares de indígenas com rostos cobertos, do Exército Zapatista de Libertação Nacional (EZLN), tomaram as principais cidades do Estado de Chiapas no México. Em novembro de 1999, ocorreram as manifestações contra a Organização Mundial do Comércio em Seattle. Em setembro de 2000, foram as manifestações em Praga contra a reunião do Fundo Monetário Internacional e do Banco Mundial. Em julho de 2001, houve as manifestações contra a reunião do G8, em Gênova, e ainda no mesmo ano, se realizou o primeiro Fórum Social Mundial (FSM), em Porto Alegre. É preciso também mencionar insurreições populares como a de Cochabamba, na Bolívia, em 2000, contra a privatização da água; as grandes marchas do Movimento dos trabalhadores Sem Terra no Brasil (MST) no final da década de 1990; organizações panamazônicas; luta dos povos afegãos e palestinos; revoltas do povo argentino através de panelaços; entre outras.
} 
participação numa manifestação em Lisboa no dia 12 de Março de 2011. O Movimento $12 \mathrm{M}$, autointitulado "apartidário, laico e pacífico", reivindicava melhorias nas condições de trabalho, principalmente para os jovens. Nessa mesma linha, a Espanha vivenciou protestos, como, por exemplo, Movimento 15-M, Indignados e Revolução Espanhola. Esse movimento, também catalisado pelas redes sociais, começou em 15 de Maio de 2011 e se caracterizou por uma série de protestos, também apartidários, laicos e pacíficos, que exigiam "Democracia Real Já!". As ações extrapolaram a Espanha e muitos outros países organizaram protestos inspirados pelos "Indignados". Seguindo a mesma linha desses protestos, em setembro do mesmo ano, surgiu em Nova York o movimento Ocupe Wall Street, que protestava contra a crise financeira e o poder econômico estadunidense.

É sabido que na literatura especializada há uma tipologia dos movimentos sociais (GOHN, 1997 e 2017; SANTOS, 2005 e 2010). Enquanto os "movimentos sociais" são aqueles pautados na luta de classes e na relação de trabalho, organizados a partir dos sindicatos e partidos políticos, os "novos movimentos sociais" são aqueles cujas fontes dos conflitos sociais enfatizam a cultura, a identidade, a esfera dos micropoderes, ou seja, mobilizam questões como, por exemplo: gênero, raça, etnia e identidade cultural. O que a teoria dos novos movimentos sociais deseja evidenciar é que, nos últimos 30 anos, as lutas mais avançadas foram protagonizadas por grupos sociais - indígenas, campesinos, mulheres, afrodescendentes, desempregados - cuja presença na história não foi visibilizada pela teoria crítica eurocêntrica.

Seguindo a tipologia, as experiências contemporâneas de rua são os chamados "novíssimos movimentos sociais", como dito anteriormente (GONH, 2017). Ao contrário dos "novos movimentos sociais", fortemente embasados em lutas identitárias, parece existir nas reivindicações contemporâneas lutas contraidentitárias, sem que, para isso, os principais objetos de interesse dos "novos..." sejam menos protagonistas.

O MOE parece bem representado por esse universo de sentidos por: a) ele não estar pautado nas relações de trabalho, mas, ao mesmo tempo, não ter isso como elemento menor, haja vista os fortes vínculos entre o MOE e os movimentos de resistência estudantil contra as más condições de trabalho ou o péssimo transporte público nas grandes cidades brasileiras; b) ele não ser a expressão das lutas identitárias 
tão características dos movimentos de contracultura e os já clássicos "novos movimentos sociais", mas, ao mesmo tempo, produzir para esses sujeitos políticos um lugar de fala dentro das pautas do $\mathrm{MOE}$, facilmente visualizáveis nos materiais gráficos produzidos ou em manifestações de apoio e/ou espaços dentro das atividades do movimento; e c) ter como elemento propulsor a questão urbana contemporânea, eventualmente articulada a partir da luta por direito à cidade, mas, concomitantemente, discutindo a cidade para além do direito, como suas políticas de uso e diagramas possíveis para uma outra cultura política da cidade.

A esta altura, uma pergunta se faz importante: como definir, então, quem são os sujeitos que fazem o MOE? A dificuldade de produzir respostas precisas para essa questão é, do nosso ponto de vista, uma das maiores ferramentas políticas do movimento, haja vista que sua composição difusa produz uma miríade de tipificações pelo poder do Estado e seus dispositivos de polícia - que vão desde a própria política militar aos veículos de mídia. De maneira geral, a tipificação mais comum para os membros do MOE é a de que são todos estudantes, geralmente ligados às áreas das humanidades e pouco concentrados no cuidado com a trajetória acadêmica. O recurso do típico para produzir lugares políticos possíveis para suas oposições foi e é um importante instrumento para diminuir a potência política das resistências. Não é diferente quando os grandes jornais da cidade recorrentemente apresentam os sujeitos das ações do movimento a partir de algum nível de conexão ora com atividades marginais - criminosas, negativamente valoradas, fácil objeto do preconceito de parte da opinião pública -, ora com a pecha de estudantes ou desempregados desocupados que criam obstáculos para o desenvolvimento urbano.

Tanto durante os dois acampamentos montados, quanto nas diversas manifestações organizadas pelo $\mathrm{MOE}$, era possível observar a presença majoritária de estudantes universitários, mas reforçada por professores, profissionais do campo da cultura, artistas populares e militantes de movimentos sociais transversais, além de moradores da região e lideranças comunitárias. Diante de perfil tão heterogêneo, o debate sobre as conduções políticas do MOE sempre foi difícil, contudo, bastante diverso e rico. Dois vídeos produzidos por pessoas ligadas ao movimento traduzem bem isso. 
O primeiro deles, "Recife, cidade roubada", publicado em 18 de novembro de 2014, realizado por Ernesto de Carvalho, Leon Sampaio, Luis Henrique Leal, Marcelo Pedroso e Pedro Severien, é um vídeo de pouco mais de 13 minutos de duração e que pretende apresentar a lógica da especulação imobiliária da cidade e como ela tem produzido segregação urbana - e pretende aprofundar seu esforço de produção. Segundo descrição do próprio grupo, trata-se de “... mais uma contribuição para demonstrar a ingerência do capital imobiliário na política urbana e a urgente necessidade de cancelamento do Projeto Novo Recife..." ${ }^{9}$. Narrado pelo ator Irandhir Santos, o texto apresenta, em tom incisivo e com conteúdo moderadamente acadêmico, uma discussão sobre o conceito de cidade do PNR e a importância de impedir a sua continuidade, reivindicando, em seu lugar, a realização do Projeto Recife, cujo conceito não fica claro - ao menos não no vídeo. Desde sua publicação, já houve mais de 222 mil visualizações no e um sem número de veiculações em TVs nacionais e internacionais.

O segundo vídeo produzido pelo movimento é o "Novo Apocalipse Recife"10, publicado em 14 de maio de 2015, assinado apenas pelo MOE e pela Troça Carnavalesca Mista Público-Privada Empatando Tua Vista ${ }^{11}$. O vídeo é uma paródia da canção "Recife, minha cidade", 1972, de Reginaldo Rossi. O texto utiliza o humor como recurso para, em tom de escárnio e com muitas referências populares, traçar um perfil político do prefeito da cidade, Geraldo Júlio (PSB), comprometido com uma lógica de desenvolvimento cultural articulada à intensa especulação imobiliária (SÁ BARRETO; MEDEIROS, 2017), tomada de forma paradigmática a partir dos interesses em ainda maior verticalização na cidade. Desde a publicação, o vídeo teve mais de 57 mil visualizações.

Os dois vídeos apresentam estratégias diferentes para lidar com a crítica que desejam produzir. Os objetivos são bem similares, mas as escolhas técnicas e os

\footnotetext{
${ }^{9}$ Vídeo disponível em https://youtu.be/dJY1XE2S9Pk.

${ }^{10}$ Vídeo disponível em https://youtu.be/uEOwJi6xNBk.

${ }^{11}$ Segundo descrição do próprio grupo, "a Troça Carnavalesca Mista Público-Privada Empatando Tua Vista é um ato político-folião crítico à verticalização excessiva, que negligencia o planejamento urbano, a história do lugar, privatiza o descortinar das águas, a paisagem e a vista dos monumentos" (ACIOLI, 2017). Em 2016, ainda no primeiro dia de carnaval, a TCMPPETV teve seu material brincante confiscado por agentes da PCR, gerando grande revolta de seus membros e simpatizantes. Ao final dos dias de festa, o Estado se pronunciou dizendo que não sabia de quem tinha partido a ordem para o confisco. Sobre isso, ver: http://tvjornal.ne10.uol.com.br/noticia/ultimas/2017/02/25/folioes-denunciam-quetiveram-fantasias-confiscadas-por-policiais-29265.php.
} 
discursos montados demonstram o caráter difuso do movimento e suas táticas políticas. No primeiro caso, um traço mais acadêmico apresenta o desenvolvimento da lógica da verticalização acompanhada pelas intervenções públicas que otimizam a circulação de automóveis. O segundo vídeo, por sua vez, manipula o escárnio como dispositivo político e procura atingir parcela da população não convencida pelo discurso acadêmico, utilizando-se para isso da paródia de canção de grande apelo popular. As demais produções do MOE descrevem diferenças políticas pontuais equivalentes, algo já visualizável desde os acampamentos, quando as assembleias eram marcadas por divergências de mesma ordem. Rodas de diálogo, piqueniques ou mesmo um ensaio fotográfico de nus em vagões abandonados demonstram minimamente essa diversidade.

Quem são os sujeitos políticos do MOE, alguém pode ainda perguntar? Isso é o que menos importa. Mas podemos arriscar que o caráter difuso da composição dos sujeitos do movimento é um recurso poderoso para a articulação de novas agências políticas. Se, a esta altura, afirmamos que a ocupação é uma nova linguagem de resistência, precisamos também compreender as sofisticações das dinâmicas de segregação urbana. Em seção anterior, já apontamos alguns caminhos, mas é justamente sobre este tema de que trata a seção a seguir.

\section{QUANDO A SEGREGAÇÃO SOCIAL SUBTRAI OS ESPAÇOS DA CIDADE: A SEGREGAÇÃO URBANA COMO OBJETO}

O conflito envergonha. Essa máxima poderia definir parte das relações que produzem a moderna urbanização nas principais cidades brasileiras. São cidades construídas para uma experiência idílica de paz, tendo o paradigma da vigilância como ponto de partida. Avenidas largas, zonas controladas pelo sanitarismo, circulação administrada pela distribuição social dos espaços de moradia e de uso público. A "nova" cidade brasileira foi construída para evitar ou criminalizar os levantes contra seus funcionamentos.

A passagem da Revolta da Vacina é mais que suficiente para visualizar tal empreendimento. As barricadas em ruas apertadas convertiam-se em zonas de front contra as quais era difícil, por parte da autoridade estatal, lutar. Dirimir a capacidade 
de mobilização da população precisava se converter em (ou se confundir com) paradigma da cidade brasileira do século XX (SEVCENKO, 2010). A gestão da vida pela saúde pública foi, naquele conjunto de eventos iniciados no aparentemente longínquo 1904, um não pouco importante pano de fundo para complexa agenda de intervenções urbanas que pretendiam, de um lado, otimizar os usos da cidade para a o mercado e, de outro lado, "qualificar" os lugares para a boa vida e consumo coletivos. A cidade como produto da força do poder militar dos primeiros governos republicanos - concentrados na destruição do Outro estrangeiro ${ }^{12}$ - convertia-se em complexo empreendimento policial que observava na gestão da vida e administração das zonas de convívio seu mais destacado objeto.

Não por acaso, podemos afirmar que o fenômeno da urbanização no Brasil é, por excelência, um traço do século XX. Em primeiro lugar, por conta do adensamento populacional. Até 1872 , apenas $5,9 \%$ da população vivia nas cidades. Em 1900, na virada de século, esse percentual era de 9,4\% (SANTOS, 2013). Em 2010, esse número já era de $84,3 \%$. Estima-se que, em 2017, estejamos próximos dos $90 \%$ de população urbana no Brasil. Isso ainda não é tudo. Em segundo lugar, mesmo conservando a tradição agroexportadora, o Brasil conduziu à cidade a posição de lócus da condução política do nacional, verificável, por exemplo, na complexa tradução freyriana da colonial Casa Grande no republicano Sobrado. Milton Santos (2013) entende esse traço como indicativo de um país gerido por hábitos agrários, que efetivamente só superou a herança da tradição agrícola com a experiência da vida urbana do século XX. Se, poucos concentrados na produção agrícola, deslocamos o foco de observação para o léxico do colonial, podemos inferir uma formação das grandes cidades brasileiras intensamente pautada no traço da experiência política colonial em complexa atualização, traduzida nos dispositivos de segregação urbana ao longo do século XX e início do XXI. Em outras palavras, afirmamos que a recente urbanização brasileira tem como característica estruturante a conservação das relações sociais coloniais, que funcionam como mecanismos de produção de lugar na cidade brasileira do século XX (SÁ BARRETO; MEDEIROS, 2017).

A cronologia de Teresa Caldeira (2000) para a segregação social, objetivada no espaço urbano, é um forte indicativo disso. Segundo a antropóloga, entre 1890 e 1940,

\footnotetext{
12 Observar o caso, por exemplo, da Guerra de Canudos, 1896.
} 
a urbanização da cidade de São Paulo descreve lugares compartilhados por moradias de populações de baixa renda e de grupos de elite. Entre 1940 e 1980, essa característica foi sendo radicalmente transformada por uma forte periferização das moradias populares, o que marcou geograficamente uma óbvia cisão entre zonas ricas e pobres das grandes cidades - São Paulo, no caso da análise de Caldeira (2000). Por fim, entre 1980 e 2000, segundo a mesma cronologia, é observado o nascimento dos enclaves fortificados como novo paradigma urbano para a maior cidade do país, modelo facilmente visualizável em cidades como Rio de Janeiro, Salvador e Recife.

Nos três recortes em questão, as políticas de segregação urbana foram sendo sofisticadas por uma narrativa do crime como razão fundamental para a apartação das populações e progressiva elaboração de políticas agressivas de segurança que visavam garantir a distinção entre as elites e as classes baixas nas grandes cidades. 0 argumento de Caldeira (2000) é de que o crime é a razão formal para uma complexa política de distinção que não estaria simplesmente traduzida no letramento, mas no acesso ao consumo de bens específicos às classes. O crime a que ela se refere é aquele que se materializa recorrentemente nos ditos "delitos cotidianos": roubos e furtos, assassinatos, tráfico de drogas, violências sexuais etc. É supostamente como dispositivo de prevenção a esses que se verifica o movimento de periferização das populações mais pobres e elitização dos bairros mais ricos nas metrópoles, consagrando o projeto do enclave fortificado, tão característico da cidade brasileira de fim de século.

O "crime como recurso", pautando a urbanização brasileira, produz, contudo, uma esfera da criminalidade mais dilatada do que essa, convertendo, paradigmaticamente, o conflito - e especificamente o conflito nas ruas - em ação criminosa contra a qual a cidade precisa lutar. A cidade não pode tolerar as ruas, exceto se elas forem uma grande celebração que projeta um reset político estratégico, como visualizamos ainda na seção anterior deste trabalho. Fora desse diagrama, toda mobilização deve ser criminosa, uma ameaça ao pertencimento nacional e a um programa de paz para as cidades estruturado nas complexas traduções da experiência política colonial contemporânea (SÁ BARRETO, 2012).

O caso de Brasília é o grande paradigma desse empreendimento. Em primeiro lugar, a transferência da capital do Rio de Janeiro para um Centro-Oeste ainda com 
números de densidade populacional baixo representa forte indicativo disso simplesmente pela transferência em si. Mudar o endereço da capital significaria - e efetivamente significou - atenuar as pressões políticas sobre os poderes nacionais. Brasília ainda é muito longe. Além disso, no entanto, em segundo lugar, tratou-se de um projeto para as ruas. Certamente o urbanismo monumental e lecorbusiano de Lúcio Costa traduz um sentido de uso da rua e vida e consumo coletivos afinados a um princípio de cidade que teria, no mínimo, a antipatia ao conflito como dispositivo. Brasília é uma cidade propícia para controlar multidões. Na recente votação pelo impedimento da Presidente Dilma Rousseff, por exemplo, a polícia "organizou" os lados militantes opostos, separados por uma "zona de segurança" que bem demonstra essa capacidade de gerir as tensões políticas. Apesar de ser Brasília o exemplo tópico, a mesma lógica pode ser verificada, com multifacetados funcionamentos, em outras grandes cidades brasileiras.

Recife, nesse contexto, empreende esse movimento de interdição das ruas como produto fundido a seu programa de moderno crescimento. Já nas intervenções dos anos 1910, o discurso higienista pretendia reverter o empobrecimento do Bairro do Recife com a derrubada do casario colonial e sua substituição por edifícios de arquitetura eclética, avenidas amplas e renovação do comércio local. O modelo deveria ser copiado para o restante da cidade em expansão, seguindo os braços de uma urbanização tentacular ${ }^{13}$ que localiza estrategicamente as zonas pobres da cidade. Nas grandes intervenções do final dos anos 1930, sobre os bairros ainda de centro de Santo Antônio e São José, desta vez mobilizado pelo discurso nacionalizante do Estado Novo, o movimento foi o mesmo, porém acompanhado por fortes investimentos na abertura de avenidas seguindo o plano tentacular, ratificando as zonas distantes do centro como regiões viáveis para as populações mais pobres. Claro que o aumento populacional é uma importante variável ${ }^{14}$, mas, nesse caso, insuficiente para explicar as lógicas de ocupação do espaço na cidade.

\footnotetext{
13 "A cidade tentacular" é como ficaria conhecida a projeção cartográfica da expansão de Recife no século XX, dirigida por grandes vias a zonas de periferia em cada uma das regiões da cidade: Boa Viagem e Imbiribeira (sul); Afogados (sudoeste); Várzea e Madalena (oeste); Casa Amarela (noroeste); Beberibe e Encruzilhada (norte).

${ }^{14}$ Recife passou, na década de 1920, de 238 mil a 348 mil habitantes, nos anos 1940.
} 
Em 1939, os mocambos representavam $67 \%$ das edificações recifenses (PONTUAL, 2001). Na década seguinte, houve uma destacada atuação, incentivada pelo Estado e por grupos religiosos da cidade, da Liga Social Contra o Mocambo, organização que agia na complexa produção das zonas de mocambo enquanto zonas de degradação do espaço urbano. É preciso salientar, neste debate, que esse tipo de edificação nunca se traduziu em uma herança arquitetônico-urbanística da cidade do Recife, ainda que seja evidente sua relevância para a história sociocultural do processo de urbanização da cidade. Pelo contrário, é bastante claro que esse traço da ocupação do espaço e produção dos lugares urbanos representava uma cidade silenciosa que deveria desaparecer, visto que não seria compatível com o projeto nacionaldesenvolvimentista em curso. Não por acaso, nos primeiros anos da década de 1940, a diretoria responsável pela gestão das ações da LSCM era também responsável pela gestão de crimes e delitos urbanos: Diretoria de Reeducação e Assistência Social (SÁ BARRETO; MEDEIROS, 2016).

Há aí um importante conjunto de léxicos e processos aos quais dizem respeito: pobreza, mocambo, degradação, crime e assistência social, que estão ligados pelo fio de Ariadne da segregação urbana na cidade do Recife, mas não somente. Dessa maneira, zonas pobres são facilmente consideradas regiões degradadas da cidade e, assim, facilmente compreendidas enquanto lócus excelente de crimes e delitos, demandando deslocamentos populacionais estratégicos e fortificações de zonas de apartação. Estas, gradativamente, deixam de ser restritas aos altos muros dos edifícios - os enclaves fortificados de Caldeira (2000) -, convertendo as políticas de exclusão em novíssimo projeto de cidade, tal qual o PNR. Não podemos mais simplesmente falar em grandes edifícios com muros que chegam aos dez metros de altura, mas de novos bairros inteiros construídos para uma "outra experiência de cidade", zonas "proto-urbanas", onde vida e consumo coletivos são administrados pela gestão privada. Na cidade em questão, é o caso da região do Paiva - uma praia cujo acesso é dificultado por uma rodovia com pedágios - e de condomínios de edifícios que se lançaram no desafio de simular completamente a experiência urbana: Evolution Shopping Park ou Le Park residencial.

O PNR é ainda a sofisticação dessa lógica, pois se projeta como peça de desenvolvimento cultural da cidade. O que está em jogo no debate contemporâneo 
sobre a revitalização urbana? A destituição do valor político do lugar, produzindo, sob o léxico da degradação, zonas disponíveis para a especulação (PEIXOTO, 2009). Para tanto, o reforço nas lógicas de invisibilidade da desigualdade e de criminalização das tensões urbanas são os braços mais destacados do poder do Estado (SOUZA, 2009). Esse esforço funciona como instrumento de ataque à crítica, produzindo-a como apelos negativos daqueles que supostamente não desejam o desenvolvimento da cidade.

Diante disso, o que significa politicamente o "degradado" da famigerada degradação urbana? Tal qual as zonas de ilegalidade da cidade (MARICATO, 2013), o degradado é um instrumento político estratégico da gestão com a finalidade de produzir insegurança urbana para populações em situações de risco. Não se pode afirmar, no entanto, que as zonas de abandono traduzem a falta de compromisso da gestão com um urbanismo pautado na realidade concreta da cidade (MARICATO, 2013). Pelo contrário, a construção política do degradado traduz, na cidade brasileira do século XX e, de forma mais complexa, na do século XXI, o urbanismo de suplício como traço da produção da cidade contemporânea, um urbanismo de punição, de condenação da pobreza (WACQUANT, 2005 e 2008).

Regiões empobrecidas próximas a áreas de potencial interesse imobiliário, então, são convertidas em - e não simplesmente identificadas como - zonas de degradação. É o que Wacquant (2005) chama de processo de desproletarização das periferias, reforçando-as como "zonas cegas", "zonas cinzas" da cidade (MONTALDO, 2010; SARLO, 2005). O antigo pátio ferroviário da antiga RFFSA é um ótimo exemplo disso. Durante anos, a região permaneceu abandonada pelo interesse público, o que culminou com um leilão fraudulento e silencioso. Em diversas enquetes organizadas pelos jornais pernambucanos, a população manifestou apoio a intervenções na região simplesmente pelo fato de se reconstruir sobre uma zona de "degradação". Poderíamos concluir, assim, que os $40 \%$ da população brasileira em terras invadidas (MARICATO, 2013) não são produto da inoperância do Estado, simplesmente, mas o resultado de uso estratégico da fragilidade política da diferença. Para o Cais José Estelita, o entendimento do poder público é o de que grandes torres de prédios e jardins são melhores do que o abandono de todo o terreno. Exime-se, dessa forma, o compromisso da gestão pública com a administração da área, se inviabiliza qualquer 
projeto arquitetônico-urbanístico destinado a outro perfil populacional e se limita a construção de significados, por parte dos atores sociais, em relação aos lugares possíveis para aquele espaço urbano e o seu entorno.

\section{“OCUPE ESTELITA!” COMO LINGUAGEM POLÍTICA DE RESISTÊNCIA}

Segundo pesquisa do IPEA referida no Diario de Pernambuco em 28 de Agosto de 2017, o Recife é a cidade que descreveu maior queda nos índices de qualidade de vida entre dez capitais brasileiras analisadas, entre 2011 e 2015, para a construção do novo Atlas da Vulnerabilidade Social. Quatro das cidades estudadas apresentaram aumento da vulnerabilidade no recorte em questão: São Paulo $(2,4 \%)$, Fortaleza (3,9\%) e Porto Alegre (0,4\%). Recife, por sua vez, indicou um aumento de $16,3 \%$, ou mais de quatro vezes o índice da segunda pior região metropolitana no recorte. Segundo números oficiais da Secretaria de Defesa Social do Estado de Pernambuco, houve 2876 homicídios em todo o Estado durante os primeiros seis meses de 2017, número 39,3\% superior aos 2063 no mesmo período em 2016. A média de assaltos a ônibus é de 16 por dia em 2017, números que talvez fizessem os dados do IPEA serem ainda piores. Muitas são as assertivas possíveis a partir desses dados. A primeira delas é a de que o projeto de segurança pública no Estado fracassou, o que intensificou os delitos e expôs a vulnerabilidade social. Essa, no entanto, é uma conclusão apressada.

Em primeiro lugar, é necessário dizer os índices de homicídio descrevem uma incrível seletividade. As zonas mais afetadas pelas mortes violentas são regiões de periferia da cidade. Os bairros de classe média seguem com baixos índices, o que representa, tomando toda a cidade como referência, uma intensa ampliação das zonas de indiferença política para o projeto de cidade. Os governos parecem - mas apenas parecem - ter relegado as periferias a própria sorte, ou falta dela.

Esse movimento, em segundo lugar, contudo, é acompanhado, na primeira década do século XXI, por profundo aquecimento do mercado imobiliário, verticalização acelerada em bairros de antigas periferias da cidade e a abertura de um mercado de grandes torres de luxo em bordas d'água na cidade - mar e rio -, processo, desde o início do século, acompanhado por pontuais intervenções viárias 
para otimizar a iniciativa do mercado imobiliário. Dois casos são, nesse aspecto, paradigmáticos.

Em 2003, a PCR deu início ao programa Recife Sem Palafitas, que pretendia atender 72 mil pessoas ( $5 \%$ da população da cidade), construindo habitações populares e removendo comunidades das "insistentes" zonas de mocambos da cidade. Moradores de margem d'água da Avenida Beira Rio, importante via que corta as zonas sudoeste e noroeste da cidade, por exemplo, foram deslocados para a região de Monsenhor Fabrício, zona oeste do município. As moradias tinham 39,39 $\mathrm{m}^{2}$, a um custo médio de $\mathrm{R} \$ 14.150,00$ (OLIVEIRA, 2004). Populações ribeirinhas, dependentes da pesca artesanal, foram deslocadas para regiões distantes das zonas dos braços de mar onde viviam antes. As medidas foram, à época, bastante comemoradas pela opinião pública e pelo discurso governamental. Pouco ou nada se via, naquela iniciativa, de uma lógica orientada pela especulação. Menos de uma década depois, no entanto, os conjuntos habitacionais populares se converteram em objeto do esquecimento das gestões municipais e não são poucos os esforços para compreender o processo (LIMA, 2014). As regiões "revitalizadas", contudo, aprofundaram a especulação do mercado imobiliário, revendo seus planos de circulação de pessoas e abertura de novas vias para comportar ainda mais carros. A "nova" Avenida Beira Rio se transformou em um dos metros quadrados mais caros da cidade. Recife sem palafitas representa, com a roupagem de complexo projeto de habitação popular e qualidade de vida dos mais pobres, uma bem costurada atualização da LSCM, aprofundando zonas de cisão entre o - sempre Novo - Recife e a interdição da experiência urbana.

O outro caso paradigmático é aquele que resume a construção da Via Mangue, maior obra viária das últimas décadas da história da cidade, com custo total de $\mathrm{R} \$$ 431,04 milhões e um pouco mais de 4 km de extensão, inaugurada em janeiro de 2016. A via expressa - ou quase expressa - liga a região dos bairros do Pina ao final de Boa Viagem, zonas compreendias por dois shoppings centers e um conjunto habitacional de luxo, destruindo parte do maior manguezal urbano do país e removendo comunidades que ocupavam a região há cinquenta anos. A obra abre espaço para 
aceleração da verticalização na região ${ }^{15}$, com forte especulação imobiliária e mais-valia do solo.

Os dois exemplos em questão aprofundam a cidade do Recife como cidade que se modernizou sofisticando suas políticas de segregação e silenciando iniciativas que se apresentem como sintomas de reversão desse empreendimento. É justamente nesse movimento que se localiza o MOE. Sua composição difusa contribuiu, e o segue fazendo, para construção de um sem número de materiais, com abordagens diversas, a fim de contestar e fazer explícito um processo que quase sempre é tido como a natural mudança silenciosa das cidades. Grosso modo, o MOE projeta a reverão do urbanismo de suplício como dispositivo estruturante do projeto de cidade. Ainda que isso efetivamente não tenha se dado, o movimento vem obtendo importantes conquistas ao expor a lógica em questão e frear o processo, ora com imbróglios legais, ora com a movimentação de rua que culminou com o acampamento em 2014, mas também se verifica em vários protestos organizados e a recorrente ocupação da rua como linguagem política central.

As torres do Cais José Estelita - curiosamente, engenheiro bastante contestador das intervenções a partir do final dos anos 1920 na cidade - tinham obras com conclusão previstas para 2012. Nada foi construído ainda e a resistência traduzida nas ruínas dos galpões do terreno está distante de narrar o vazio que representavam antes do MOE. A crise econômica na qual o país mergulhou a partir de 2011 explica parte do atraso. Grandes edifícios, em contrapartida, continuam sendo erguidos na cidade, alguns em regiões cuja interferência na paisagem urbana é ainda maior. 0 MOE tem organizado uma série de atividades contra essas intervenções, intensificando o exercício de exposição da lógica em questão, o que se consolida e se expande para além da zona do cais.

\footnotetext{
15 Os bairros em questão, Pina e Boa Viagem, já eram bastante verticalizados. Os prédios de gabarito mais alto normalmente se restringiam às principais vias e às proximidades da praia. No entanto, o que observamos atualmente é uma verticalização que avançou para além das vias principais e tomou outros bairros - inclusive menos valorizados anteriormente pelo mercado imobiliário. Além disso, é preciso destacar que esse padrão de verticalização trouxe um modelo construtivo de prédio "fálico": quanto mais alto, melhor. No entanto, enquanto boa parte da área "nobre" da zona norte da cidade foi preservada devido à Lei Municipal $n^{\circ}$ 16.719/2001, conhecida como Lei dos 12 bairros, que limita o gabarito de altura das edificações, o resto da cidade ficou subjugado à selvageria dos capitais fundiário e imobiliário.
} 
A ausência das bandeiras nacionalistas, de um lugar de identidade cultural consolidado, e de um vínculo explícito entre o MOE e os "novos movimentos sociais" produzem o lugar do meio como elemento intensamente característico dos deslocamentos contemporâneos de sentido para os quais as discussões de Bhabha (1998) chamam atenção. Um pensamento de fronteira, uma força política de bordas, ou mesmo as "zonas cinzas" da Buenos Aires de Beatriz Sarlo (2005), indicam importantes manchas nas traduções mais recorrentes das grandes mobilizações; borras a partir das quais um novo vocabulário para as ruas se faz imperativo do tempo. É isso que a ocupação contemporânea pretende mobilizar e que produz o MOE como esforço para desvelar uma lógica e produzir a rua como objeto da profanação (AGAMBEN, 2007).

As contradições de um tempo regido pelo lugar comum do consumo parecem estar abrindo fendas cognitivas no seio de uma tradição de interpretação dos movimentos sociais e suas formas de mobilização dos/nos espaços públicos. As possibilidades para a constituição de uma nova experiência das ruas parece se fortalecer ora quando não funciona a partir dos discursos de restituição do nacional, ora quando se descola das demandas exclusivas do mundo burguês por uma gentrificação das grandes metrópoles ocidentais. O MOE traduz esforços nas duas frentes, mas não com uma agenda clara. Esta, por sua vez, pauta fundamentalmente as resistências urbanas contemporâneas: o desafio de atualizar, seja na luta por direito à cidade, seja nas lutas pela cidade além do direito, linguagens de uso dos lugares, da produção da cidade como resultado de tensões às quais o projeto de brasilidade estrategicamente nega visibilidade. Essa reversão da segregação urbana tomada como desenvolvimento cultural configura-se como grande contribuição do MOE à medida que denuncia a rua como zona de interdição, por um lado, e contesta uma lógica que suprime a experiência urbana muito antes do nascimento do PNR, por outro.

Após todo esse debate, voltamos, então, à destruição do acampamento do Ocupe Estelita para dizer que aquela ação deveria servir a complexo empreendimento de silenciamento da ação coletiva que se materializava no acampamento. Embora fosse economicamente importante para o consórcio reintegrar a posse dos galpões do Cais José Estelita, e politicamente necessário para a prefeitura da cidade, era apenas objetivo secundário do poder estatal. Mais importante que isso, àquela altura, era 
efetivamente diminuir o potencial político do conjunto de manifestações e desarticular aproximações ainda difusas de interesses e políticas de usos diversos sobre a cidade. Se disponibilizar o espaço para a produção do Novo Recife era já urgente naquele junho de 2014, ainda mais imediato que isso deveria ser o desmantelamento de um movimento que poderia dar formas a uma nova agência política na cidade. E deu!

\section{REFERÊNCIAS}

ACIOLI, Maíra. Empatando tua vista. Blog Direitos urbanos, 21, fev. 2017. https://direitosurbanos.wordpress.com/empatando-tua-vista/. Acessado em 15 de julho de 2020.

AGAMBEN, Giorgio. Profanações. São Paulo: Boitempo, 2007.

BHABHA, Homi. O Local da Cultura. Belo Horizonte: Ed. UFMG, 1998.

BENZAQUEN, Júlia Figueiredo; SÁ BARRETO, Francisco. A mão dupla da rua: a ambivalência da "nova resistência" ou elementos para uma outra gramática da mobilização. Estudos de Sociologia, v. 2, n. 19, abr. 2015.

CALDEIRA, Teresa Pires do Rio. Cidade de Muros: crime, segregação e cidadania em São Paulo. São Paulo: Ed. 34, 2000.

GOHN, Maria da Glória. Teoria dos movimentos sociais: paradigmas clássicos e contemporâneos. São Paulo: Edições Loyola, 1997.

Manifestações e protestos no Brasil: correntes e contracorrentes na atualidade. São Paulo: Cortez, 2017.

HABERMAS, Jürgen. Mudança estrutural da esfera pública: investigações quanto a uma categoria da sociedade burguesa. Rio de Janeiro: Tempo brasileiro, 2003.

JACOBS, Jane. Morte e vida de grandes cidades. São Paulo: Martins Fontes, 2014.

JEUDY, Henri-Pierre. Espelho das cidades. Rio de Janeiro: Casa da Palavra, 2005.

LEITE, Rogério Proença. Contra-usos da cidade: lugares e espaço público na experiência urbana contemporânea. Campinas: Unicamp, 2007.

LIMA, Antônio Marques. A dinâmica da relocação do Residencial Via Mangue III: um estudo sobre a formação da identidade comunitária. 2014. Trabalho de Conclusão de Curso em Ciências Sociais - Departamento de Antropologia e Museologia, Universidade Federal de Pernambuco, Recife. 2014.

MARICATO, Ermínia. Brasil, cidades: alternativas para a crise urbana. Petrópolis: Vozes, 2013.

MONTALDO, Graciela. Zonas ciegas: populismos y experimentos culturales em Argentina. Buenos Aires: Fondo de Cultura Económica, 2010. 
OLIVEIRA, Fernanda Martinez. Inclusão social a partir do direito à moradia: Programa Recife sem palafitas. Cadernos Gestão Pública e Cidadania, v. 9, n. 44, nov. 2004, p. 7-22.

PEIXOTO, Paulo. Requalificação Urbana. Em: FORTUNA, Carlos; PROENÇA-LEITE, Rogério (Orgs.). Plural de Cidade: léxicos e culturas urbanas. Coimbra: Almedina, 2009.

PONTUAL, Virgínia. Uma cidade e dois prefeitos: narrativas do Recife das décadas de 1930 a 1950. Recife: Ed.UFPE, 2001.

SÁ BARRETO, Francisco. A dor e a delícia de ser o que: a brasilidade e o caso do pertencimento como disciplina. 2012. p. 293. Tese de Doutorado em Sociologia Programa de Pós-Graduação em Sociologia, Universidade Federal da Paraíba, João Pessoa. 2012.

SÁ BARRETO, Francisco; MEDEIROS, Izabella Maria. As cidades como objeto das políticas de cultura: o caso da Recife do século XXI. Brasília: Anais do Congresso da SBS, 2017.

. Limites e possibilidades de agências digitais para outras urbanidades possíveis - o caso do grupo de direitos urbanos em Recife, Pernambuco. REVISTA DIREITO E PRÁXIS, v. 11, p. 666-696, 2020a.

Culturas do Passado-Presente: Um estudo sobre o discurso da Novidade e as políticas patrimoniais em um Recife de três tempos. REVISTA BRASILEIRA DE PESQUISA (AUTO)BIOGRÁFICA, v. 05, p. 667-691, $2020 \mathrm{~b}$.

SANTOS, Boaventura de Sousa. Pela mão de Alice: o social e o político na pósmodernidade. 10a ed., São Paulo: Cortez, 2005.

La refundación del Estado en América Latina. Perspectivas desde una epistemología del sur. Lima, Julio de 2010. Instituto Internacional de Derecho y Sociedad. Programa Democracia y transformación global. Red latinoamericana de Antropología Jurídica (RELAJU), 2010.

SANTOS, Milton. A urbanização brasileira. São Paulo: EdUSP, 2013.

SARLO, Beatriz. Tempo Presente: notas sobre a mudança de uma cultura. Rio de Janeiro: José Olympo, 2005.

SEVCENKO, Nicolau. A Revolta da Vacina: mentes insanas em corpos rebeldes. São Paulo: Cosac Naify, 2010.

SOUZA, Jessé. A ralé brasileira: quem é e como vive. Belo Horizonte: Ed. UFMG, 2009.

VERAS, Lúcia Maria de Siqueira. Paisagem-postal: a imagem e a palavra na compreensão de um Recife urbano. 2014. p. 467. Tese de Doutorado em Desenvolvimento Urbano - Programa de Pós-Graduação em Desenvolvimento Urbano, Universidade Federal de Pernambuco, Recife. 2014.

WACQUANT, Loïc. Os condenados da cidade: estudos sobre marginalidade avançada. Rio de Janeiro: Revan, 2005.

As duas faces do gueto. São Paulo: Boitempo, 2008. 
YÚDICE, George. A Conveniência da Cultura: usos da cultura na era global. Belo Horizonte: Ed. UFMG, 2004.

ŽlŽEK, Slavoj. Multiculturalismo, ou a lógica cultural do capitalismo multinacional. Em. ŽlŽEK, Slavoj et al. Žižek crítico: política e psicanálise na era do multiculturalismo. São Paulo: Hacker Editores, 2005.

ZUKIN, Sharon. Paisagens do século XXI: notas sobre a mudança social e o espaço urbano. Em: ARANTES, Antônio. O Espaço da diferença. Campinas: Papirus, 2000. 